\title{
KAJIAN EKONOMI USAHATANI SAYUR DAUN-DAUNAN (LEAVY VEGETABLES) DI KABUPATEN ENDE
}

\author{
Philipus Nerius Supardi, Charly Mutiara \\ Program Studi Agroteknologi, Fakultas Pertanian Universitas Flores,Ende \\ Jln. Sam Ratulangi, Kel. Paupire, Kab. Ende \\ ardytobong@gmail.com,
}

\begin{abstract}
Economic Study of Leaf Vegetable Farming and Vegetable Marketing Channel Systems in Ende Regency. This study aims to conduct an economic study of leaf vegetable farming and vegetable marketing channel systems in Ende Regency. This research was carried out in several sub-districts which were the center of vegetable production in the traditionally cultivated Regency of Ende. The sub-districts that were the object of research were Kelimutu Subdistrict, Lepembusu Kelisoke, Detusoko, Wolojita. The observation variables in this study were farming income, farming costs, economic life of farming, and vegetable distribution systems. Variable analysis using financial analysis was used to determine the criteria for evaluating investment feasibility of vegetable farming. This financial analysis uses NPV and B / C Ratio. Based on the results of the research that has been done, it can be concluded that the $\mathrm{B} / \mathrm{C}$ ratio is 12.6 , which means that the vegetable farms of Ende District respondent farmers deserve to continue to be cultivated. While the NPV value is Rp. 20,912,730.34. Vegetable distribution of leaves of respondent farmers in Ende district using a direct sales system to retailers on the market. Based on the values obtained, the vegetable farms of farmers in Ende Regency are worthy to continue.
\end{abstract}

Keywords : Leaf Vegetables, Economic Analysis

\section{PENDAHULUAN}

Sayur - sayuran adalah bagian dari

kebutuhan pokok manusia untuk memenuhi kebutuhan gizi. Dalam memenuhi kebutuhan konsumen tentunya dapat dilihat dari keseimbangan antara jumlah produksi sayur - sayuran yang hasilkan dengan kebutuhan pasar. Berdasarkan jenis sayur - sayuran, dapat di identifikasi berdasarkan bentuknya, yaitu sayuran daun - daunan, sayuran buah - buahan dan sayuran umbi - umbian. Dalam penelitian ini hanya di batasi tentang sayuran daun - daunaan. Permintaan pasar lokal di dorong oleh meningkatnya kesadaran masyarakat akan pentingnya sayuran sejalan dengan peningkatan pendapatan ekonomi masyarakat. Dalam memenuhi kebutuhan konsumen di kota Ende tentunya tidak semua jenis sayur dapat di penuhi. Hal ini di sebabkan kurangnya petani produsen untuk berusaha di bidang sayur - sayuran Di Kota Ende telah terdapat sejumlah usahatani sayur - sayuran secara tradisional yang dapat memenuhi kebutuhan konsumen yang walaupun dalam jumlah yang terebatas. Perkembangan usahatani sayur - sayuran di Kota Ende berada di daerah pinggiran kota yang sekala usahanya relatif kecil dan terbatas pada teknologi budidaya yang 
sederhana. Adapun sentra produksi sayur sayuran di Kota Ende tersebar di beberapa kecamatan. Minat petani untuk berusaha dibidang sayur - sayuran di kabupaten Ende masih sangat rendah, hal ini di karenakan usaha sayur - sayuran belum mampu untuk menopang kehidupan konomi rumah tangga. Dari permasalahan ini maka perlu melakukan kajian secara ekonomi usahatani sayur daun - daunan di kabupaten Ende.

Untuk pertumbuhan dan pengembangan agribisnis yang berdaya saing di Kota Ende, harus di perhatikan berberapa hal yaitu; peningkatan produksi dan produktifitas melalui penerapan ilmu pengetahuan dan teknologi, harus memenuhi permintaan konsumen, berkualitas baik dan berkesinambungan, mempunyai nilai tambah berupa produk olahan dengan cara pengemasan yang baik, kelembagaan dengan menciptakan iklim usaha yang merangsang pertumbuhan ekonomi dan investasi.

Menjadi perhatian untuk menghadapi perkembangan pertanian di masa yang akan datang adalah mempunyai komoditas unggulan yang berdaya saing di pasar domestik maupun pasar internasinal. Hal yang tidak kalah penting adalah merubah prilaku usahatani kearah pengembangan usaha dan pengembangan pasarnya, karena usaha dan pengembangan pasar merupakan dua aspek penting dalam memanfaatkan permintaan pasar yang cendrung meningkat.

\section{METODE PENELITIAN}

\section{Lokasi Penelitian}

Penelitian ini dilakukan di beberapa kecamatan yang merupakan sentra produksi sayur-sayuran di Kabupaten Ende yang dibudidayakan secara tradisional.Adapun kecamatan yang menjadi obyek penelitian adalah; kecamatan Kelimutu, Lepembusu Kelisoke, Detusoko, Wolojita.

\section{Tahapan Penelitian}

1. Survey awal

Survey awal dilakukan untuk mengidentifikasi lokasi penelitian yang meliputi beberapa kecamatan sentra produksi sayur-sayuran di kabupaten Ende.

2. Penentuan Sampel

Penetuan sampel dilakukan untuk menentukan petani dan pedagang yang berusaha di bidang sayursayuran di kecamatan kelimutu, lepembusu kelisoke, detusoko, wolojita

3. Wawancara

Wawancara dilakukan untuk mendapatkan data yang berkaitan dengan penelitian

\section{Variabel Pengamatan}

1. Pendapatan usahatani

2. Biaya usahatani

3. Umur ekonomis usahatani

4. Distribusi sayuran

\section{Model Penelitian}

Penelitian kuantitatif dan kualitatif

\section{Tehnik Pengumpulan Data}

Data yang dikumpulkan dalam penelitian ini adalah berupa data primer dan data sekunder. Data primer diperoleh dari hasil wawancara dan pengisian kuisioner. Sedangkan data sekunder di peroleh dari instansi-instansi terkait.

\section{Analisis Data}


1. Analisis finansial digunakan untuk mengetahui kriteria penilaian kelayakan investasi usahatani sayur. Analisis finansial ini dengan menggunakan NPV dan B/C Ratio.

2. Analisis Deskriptif : analisis ini di gunakan untuk mendeskripsikan saluran pemasaran usahatani sayursayuran

\section{HASIL DAN PEMBAHASAAN}

\section{Kondisi Umum Petani Responden \\ Umur Petani Responden}

Umur petani merupakan salah satu factor penentu dalam mencapai keberhasilan dalam berusaha Tani. Dalam mencapai keberhasilan dalam berusaha tani tentu di lihat dari usia produktif atau tidaknya seorang petani dalam menjalankan usahanya

Tabel.1 : klasifikasi umur petani sayur daun - daunan di kabupaten Ende

\begin{tabular}{ccccc}
\hline NO & Kategori Umur & Klasifikasi Umur & Jumlah & Persentase (\%) \\
\hline 1 & $0-14$ & Belum Produktif & 0 & 0 \\
2 & $15-64$ & Produktif & 76 & 95 \\
3 & $\geq 65$ & Tidak Produktif & 4 & 5 \\
\hline & & & 80 & 100 \\
\hline
\end{tabular}

Usia produktif seorang petani dapat diketahui berdasarkan klasifikasi umur petani yaitu, 0 - 14 tahun termasuk dalam kategori usia belum produktif, 15 - 64 tahun termasuk dalam kategori usia produktif dan usia $\geq 65$ tahun termasuk dalam kategori usia tidak produktif, (Mantra, 2004). Untuk mengetahui umur produktif petani responden dapat di lihat pada tabel .Berdasarkan hasil penelitian, bahwa sebaran umur petani sayur daun daunan di kabupaten Ende yang terdiri dari 80 responden yaitu usia $0-14$ tahun terdapat $0 \%$, artinya tidak terdapat petani responden yang usianya belum produktif, usia 15 - 64 tahun terdapat 76 responden atau $95 \%$, dan usia $\geq 65$ tahun terdapat 4 responden atau $5 \%$. Dengan demikian, petani sayur daun daunan di kabupaten Ende masih di dominasi oleh petani yang usai produktif.

\section{Tingkat Pendidikan Petani Responden}

Pendidikan merupakan salah satu unsur penting dalam mendukung kemampuan petani untuk mendukung kratifitas petani dalam perkembangan pertanian (Tabel 2).

Tabel 2 : Prosentase tingkat pendikan formal petani sayur daun - daunan di Kabupaten Ende

\begin{tabular}{cccc}
\hline NO & Tingakat Pendidikan & Jumlah & Persentase (\%) \\
\hline 1 & SD & 43 & 53.75 \\
2 & SMP & 22 & 27.5 \\
3 & SMA/SMK & 13 & 16.25 \\
4 & Sarjana & 2 & 2.5 \\
\hline & Total & 80 & 100 \\
\hline & & inovasi baru. Semakin rendahnya \\
Dalam menjalankan kewirausahaan di & pendidkan petani maka semakin rendah \\
bidang pertanian sangat di tuntut bagi para & pula dalam penerapan teknologi baru \\
petani untuk selalu berkreatif serta & dalam bidang pertanian. Sebagai upaya
\end{tabular}


untuk peningkatan kemampuan petani dalam penerapan teknologi di bidang pertanian maka harus di dukung oleh pendidikan yang baik.Untuk mengetahui tingkat pendidkan formal petani sayur daun- daunan di kabupaten Ende dapat di lihat pada table. 2 berikut ini. Berdasarkan hasil penelitian bahwa tingkat pendidikan formal petani sayur daun-daunan di Kabupaten Ende yang terdiri dari 80 responden dimana 43 responden atau $53,75 \%$, mecapai pendikan tingkat SD tamat, 22 responden atau 27,5\% mencapai pendidkan tingkat SMP tamat, 13 responden atau 16, 25\% mencapai pendikan tingkat SMA tamat, dan 2 responden atau 2,5\% mencapai pendidikan Tingkat sarjana tamat. Dengan demikian tingkat pendidikan formal petani sayur daun- daunan di kabupaten Ende masih di dominasi oleh petani tingkat pendidkan Sekolah Dasar (SD) dengan prosentasi lebih tinggi dari tingkat pendidkan formal yang lain.

\section{Jumlah Tanggungan Keluarga}

Dalam kehidupan berumah tangga tentu ada beban yang di tanggung berdasarkan kebutuhan anggota keluarga.Jumlah anggota keluarga merupakan beban yang di tanggung oleh kepala rumah tangga Tabe 3.

Tabel 3. Porsentase jumlah tanggungan keluarga petani responden sayur daun daunan di kabupaten Ende

\begin{tabular}{cccc}
\hline NO & Tanggungan Keluarga & Jumlah & Persentase \% \\
\hline 1 & 2-Jan & 54 & 67.5 \\
2 & 4-Mar & 23 & 28.75 \\
3 & 6-May & 3 & 3.75 \\
\hline & Total & $\mathbf{8 0}$ & $\mathbf{1 0 0}$ \\
\hline
\end{tabular}

Berdasarkan hasil penelitian, jumlah tanggungan petani responden sayur daun daunan antara $1-2$ orang dari 80 responden di Kabupaten Ende sebanyak 54 orang atau 67,5\%, jumlah tanggungan keluarga antara $3-4$ orang sebanyak 23 orang atau $28,75 \%$ dan jumlah tanggungan keluarga antara $5-6$ orang sebanyak 3 orang atau $3,75 \%$. Dengan demikian jumlah tanggungan keluarga peetani responden masih di dominasi oleh jumlah $1-2$ orang. Artinya jumlah ini tidak terlalu banyak, dan hal ini sangat mempengaruhi ketersedian tenaga kerja keluarga dalam berusaha tani.

\section{Luas Lahan Petani Responden}

Jumlah produksi sayur daundaunan yang di hasilkan oleh petani sangat tergantung pada besaran luas lahan yang di siapkan. (Tabel. 4)

Tabel 4 : prosentasi jumlah petani sayur daun-daunan di Kabupaten Ende berdasarkan besaran luas lahan

\begin{tabular}{cccc}
\hline NO & Luas Lahan $(\mathrm{Ha})$ & Jumlah (Orang) & Persentase $(\%)$ \\
\hline 1 & $0.01-0.5$ & 77 & 96.25 \\
2 & $0.51-1$ & 2 & 2.5 \\
3 & $>1$ & 1 & 1.25 \\
& & 80 & 100 \\
\hline
\end{tabular}

Untuk besaran luas lahan petani responden luasannya berbeda-beda antara satu dengan yang lainnya. Hal ini di buktikan dengan prosentasi jumlah petani responden 
dengan luas lahan garapan yang tidak sama seperti pada tabel 4

Berdasarkan hasil penelitian, kisaran luasan lahan petani responden antara 0,01 - 0,5 Ha sebanyak 77 responden atau 96,25\%, kisaran besaran luas lahan 0,51 - 1 Ha sebanyak 2 responden atau 2,5\% dan besaran luasa lahan > $1 \mathrm{Ha}$ sebanyak 1 responden atau $1,25 \%$. Dengan demikian, untuk luas lahan garapan petani responden sayur daun daunan di Kabupaten Ende masih di dominasi dengan luasan lahan yang sangat kecil yaitu antara $0,01-0,5$ Ha. Sedangkan setatus kepemilikan lahan petani responden $100 \%$ milik sendiri.

\section{Pekerjaan Sampingan Petani Responden}

Pekerjaan sampingan merupakan salah satu upaya untuk menambah income petani responden, di mana pekerjaan ini dapat dilaksanakan setelah pekerjaan pokok selesai di kerjakan, atau dilaksanakan pada waktu senggang.Untuk kondisi pekerjaan sampingan petani respnden dapat di lihat pada tabel 5.

Tabel 5.: Ende berdasarkan Prosentasi jumlah petani rexponden sayur daun-daunan di Kabupaten Pekerjaan Sampingan

\begin{tabular}{cccc}
\hline NO & Pekerjaan Sampingan & Jumlah & Persentase (\%) \\
\hline 1 & Ada & 3 & 3.75 \\
2 & Tidak Ada & 77 & 96.25 \\
& & 80 & 100 \\
\hline
\end{tabular}

Berdasarkan hasil penelitian, bahwa petani responden yang memiliki pekerjaan sampingan sebanyak 3 orang atau 3,75\%, dan yang tidak memiliki pekerjaan sampingan sebanyak 77 orang atau $96,25 \%$. Dengan demikian bahwa petani responden masih di dominasi oleh petani yang focus hanya melakukan pekerjaan pokok yaitu berusaha tani di bidang sayur - sayuran.

\section{B. Sumber Permodalan}

Permodalan merupakan hal penting dalam memulai sutu usaha sayur daundauanan.Hal ini penting karena berkaitan dengan biaya yaitu biaya produksidan biaya operasional. Dari hasil penelitian bahwa sumber permodalan dari petani responden $100 \%$ bersumber dari modal sendiri dengan rata-rata jumlah modal sebesar Rp 1.818.722 dari jumlah responden xebanyak 80 responden. Dari rata-rata jumlah modal yang ada maka usaha yang di lakukan oleh petani sayur daun-daunan di Kabupaten Ende masih tergolong kecil. Hal ini di dukung oleh luas lahan garapan di mana 96,25\% masih berada pada kisaran luas $0,01-0,5$ ha. Semakin kecil luas lahan garapan semakin keci modal yang disiapkan.Sebaliknya Semakin besar luas lahan garapan semakin besar pula modal yang di siapkan.

\section{Analisis Kelayakan Finansial}

Pendekatan dalam penelitian ini di analisis dengan metode $\mathrm{B} / \mathrm{C}$ ratio dan $\mathrm{Net}$ Persent Value(NPV).

\section{Analisis $\mathrm{B} / \mathrm{C}$ ratio}

Berdasarkan hasil penelitian bahwa nilai B/C Ratio usaha tani sayur daun-daunan di kabupaten Ende sebesar 12.6.Dengan demikian usaha tani sayur daun-daunan di Kabupaten Ende layak untuk terus di usahaka 
FC (Fixed Cost)

VC (Variabel Cost)
SAPRODI

Tenaga kerja

dan

Pemasaran
Rp345,625

Rp345,625

1455990

1455990

Rp1,801,615

Rp22,714,345.34

12.6
Kelayakan suatu usaha yang di lakukan dapat dilihat berdasarkan ketententuan sebagai berikut :

- Jika B/C Ratio dalam suatu usaha > 1 maka usaha tersebut layak untuk di teruskan

- Jika B/C ratio dalam suatu usaha < 1 maka usaha tersebut tidak layak untuk terus di usahakan.

\section{Analisis Net Persent Value (NPV)}

Analisis NPV merupakan analisis yang dapat menunjukan nilai yang di hasilkan saat ini dari suatu investasi, atau perbedadaan antara nilai pasar dari suatu investasi dengan biaya yang di keluarkan.Dengan demikian NPV merupakan besarnya tingkat pengembalian dari suatu usaha. Suatu usaha layak untuk terus dilakukan jika nilai NPV > 0.Berdasarkan hasil penelitian bahawa nilai NPV sebesar Rp20,912,730.34, untuk satu kali periode tanam.Nilai ini di peroleh dari NPV = PVB - PVC. Berdasarkan nilai yang di peroleh maka usaha tani sayur daun-daunan di kabupaten Ende layak untuk terus di usahakan.

\section{Distribusi pemasaran}

Distribusi pemasaran merupakan proses pemasaran yang dapat mempermudah pendistribusian barang atau jasa dari produsen ke konsumen, sesuai dengan kebutuhan (jenis, jumlah, harga, tempat dan waktu di butuhkan ). Berdasarkan hasil penelitian pada petani responden sayur daun-daunan di kabupaten ende, 100 $\%$ mereka menjual langsung ke pasar, yaitu dari petani produsen langsung ke pedagang pengecer di pasar. Hal ini dilakukan karena kerap kali mereka sering mendapat kerugian atau harga sering di permainkan oleh pedagang pengumpul.

Menurut keterangan dari petani responden, mereka merasa lebih menguntung menjual langsung ke pasar dari pada menjual ke pedagang perantara.

\section{Simpulan}

Berdasarkan hasil penelitian yang telah di lakukan dapat di simpulkan bahwa :

1. Hasil analisis B/C Ratio menunjukan nilai Rp.12,6, yang artinya usaha tani sayur daun-daunan petani responden kabupaten Ende layak untuk terus di usahakan dan nilai NPV sebesar Rp 20,912,730.34. Berdasarkan nilai yang di peroleh maka usaha tani sayur daun-daunan petani responden di kabupaten Ende layak untuk terus di usahakan.

2. Distribusi Sayur daun-daunan petani responden di kabupaten ende dengang menggunakan system penjualan 


\section{Supardi : Kajian Usaha Tani Sayuran Di Kabupaten Ende}

langsung ke pedagang pengecer di pasar.

\section{UCAPAN TERIMA KASIH}

Pada kesempatan ini penulis ingin mengucapkan terima kasih kepada DPRM Kemenristekdikti yang telah membiayai seluruh kegiatan penelitian ini dan kepada LPPM Universitas Flores yang telah membantu dalam seluruh kepengrusan administrasinya, serta semua pihak yang telah membantu dengan caranya masingmasing dalam melengkapi tulisan ini.

\section{DAFTAR PUSTAKA}

Darmadji.2011. Analisis Kinerja Usahatani Padi Dengan Metode Sistem of Rice Intensification Di Kabupaten Sleman Daerah Istimewa Yogyakarta.Agica. Vol. 9 (2): 1-18

Hastuti E. 2008. Pengaruh Penerapan Sistem Agribisnis Terhadap Peningkatan Pendapatan Petani Sayuran Di Kabupaten Bayulali. Universitas Diponegoro. Semarang

Haryanto Eko, dkk. 2007. Sawi dan Selada. Penebar Swadaya. Jakarta

Kadariah, 2001.Evaluasi proyek: Analisis Ekonomis. Lembaga Penerbit Fakultas

Ekonomi Universitas Indonesia. Kasmir, 2003. Bank Lembaga keuangan Lainnya, Jakarta : PT Raja Grafindo

Luntungan Antonius. 2012. Analisis Tingkat Pendapatan Usahatani Tomat Apel Di Kecamatan Tamposo Kabuapaten Minahasa. Jurnal Pembangunan Ekonomi dan Keuangan Daerah. Vol. 7 (3): 1-25
Mantra,I.B. 2004. Demografi Umum. Penerbit Pustaka Pelajar. Yogyakarta

Muizah R.,Supardi S.,Awami Sofia. 2013. Analisis Pendapatan Usahatani Ubikayu.Mediagro. Vol. 9 (2): 55-67.

Saptana, dkk. 2005. Analisis Kelembagaan Kemitraan Usaha Di Sentrasentra Produksi sayuran,(suatu kajian Atas Kasus Kelembagaan Kemitraan Di Bali, Sumatra Utara, dan Jawa Barat)

Taufik M. 2012. Strategi Pengembangan Agribisnis Sayuran Di Sulawesi Selatan.Jurnal Litbang Pertanian. Vol. 31 (2): 43-50

Wiyanti Raden. 2013. Analisis Pendapatan Usahatani dan Tataniaga Buncis Organik dan Buncis NonOrganik Di Desa Cisondari, Kecamatan Pasir Jambu, Kabupaten Bandung.Fakultas Ekonomi dan ManajemenInstitut Pertanian Bogor. Bogor. 